\title{
Addressing Food Insecurity through a Health Equity Lens: a Case Study of Large Urban School Districts during the COVID-19 Pandemic
}

\author{
Gabriella M. McLoughlin (D) - Julia A. McCarthy • \\ Jared T. McGuirt • Chelsea R. Singleton • Caroline G. \\ Dunn • Preety Gadhoke
}

Published online: 21 September 2020

(C) The New York Academy of Medicine 2020

\begin{abstract}
Reduced access to school meals during public health emergencies can accelerate food insecurity and nutritional status, particularly for low-income children in urban areas. To prevent the exacerbation of health disparities, there is a need to understand the implementation of meal distribution among large urban school districts during emergencies and to what degree these strategies provide equitable meal access. Our case study of four large urban school districts during the COVID-19 pandemic aims to address these knowledge gaps. Guided by the Getting to Equity (GTE) framework, we conducted a mixed-methods study evaluating emergency meal distribution and strategy implementation in four large urban school districts (Chicago Public Schools, Houston Independent School District, Los Angeles Unified
\end{abstract}

\section{G. M. McLoughlin}

Implementation Science Center for Cancer Control and Prevention Research Center, Brown School, Washington University in St. Louis, One Brookings Drive, St. Louis, MO 63130, USA

G. M. McLoughlin ( $\square)$

Department of Surgery (Division of Public Health Sciences), Washington University School of Medicine, Washington University in St. Louis, St. Louis, MO 63110, USA

e-mail: gmcloughlin@wustl.edu

J. A. McCarthy

Laurie M. Tisch Center for Food, Education \& Policy, Teachers College, Columbia University, 525 West 120th Street, Box 137,

New York, NY 10027, USA
School District, and New York City Department of Education). We gathered data from school district websites on (1) meal service and delivery sites and (2) district documents, policies, communication, and resources. Using qualitative coding approaches, we identified unique and shared district strategies to address meal distribution and communications during the pandemic according to the four components of the GTE framework: increase healthy options, reduce deterrents, build on community capacity, and increase social and economic resources. We matched district census tract boundaries to demographic data from the 2018 American Community Survey and United States Department of Agriculture food desert data, and used geographic information systems (GIS) software to identify meal site locations

\section{R. Singleton \\ Department of Kinesiology and Community Health, University of Illinois at Urbana-Champaign, 1206 Fourth Street, Champaign, IL 61820, USA \\ C. G. Dunn \\ Department of Health Policy and Management, Harvard T.H. Chan School of Public Health, 677 Huntington Avenue, Boston, MA 02115, USA \\ P. Gadhoke \\ Department of Pharmacy Administration \& Public Health, College of Pharmacy \& Health Sciences, St. John's University, 175-05 Horace Harding Expressway Room 214, Queens, NY 11365, USA}

J. T. McGuirt

Department of Nutrition, University of North Carolina Greensboro, 319 College Avenue, 318 Stone Building, Greensboro, NC 27412, USA 
relative to student population, areas of high poverty and high minority populations, and food deserts. We found that all districts developed strategies to optimize meal provision, which varied across case site. Strategies to increase healthy options included serving adults and other members of the general public, providing timely information on meal site locations, and promoting consumption of a balanced diet. The quantity and frequency of meals served varied, and the degree to which districts promoted high-quality nutrition was limited. Reducing deterrents related to using inclusive language and images and providing safety information on social distancing practices in multiple languages. Districts built community capacity through partnering with first responder, relief, and other community organizations. Increased social and economic resources were illustrated by providing technology assistance to families, childcare referrals for essential workers, and other wellness resources. Geospatial analysis suggests that service locations across cities varied to some degree by demographics and food environment, with potential gaps in reach. This study identifies strategies that have the potential to increase equitable access to nutrition assistance programs. Our findings can support (1) ongoing efforts to address child food insecurity during the pandemic and (2) future meal provision through programs like the Summer Food Service Program and Seamless Summer Option. Future research should further examine the rationale behind meal site placement and how site availability changed over time.

Keywords Food insecurity · COVID-19 - Urban schools

\section{Introduction}

The novel coronavirus (COVID-19) pandemic has brought unprecedented challenges to schools that were forced to close to prevent further exacerbation of infection. However, students' needs pertaining to nutritional supplementation through school meals persisted despite not attending school in-person. Ensuring access to food during these critical times is of paramount importance to meeting the public health needs of vulnerable populations at greatest risk for food insecurity. Further, as schools contemplate reopening plans, a greater emphasis is placed on ways to maintain practices developed over the closure period, protecting access to supplemental nutrition.
Federal nutrition assistance programs like the School Breakfast Program (SBP) and National School Lunch Program (NSLP) help address child food insecurity [1-3] and improve access to healthy foods [4]. Nearly 30 million students participate in SBP and NSLP daily [5], and $85 \%$ of SBP and $71 \%$ of NSLP participants receive free or reduced priced meals based on household income, meaning their families do not have adequate means to purchase food in absence of safety net programs. For many students, school meals make up onethird to one-half of their caloric intake in a day [6]. Regular consumption of school meals can improve dietary intake; students who eat school meals every day consume more fruits and vegetables, fiber, and whole grains compared with those who do not [7, 8]. Accordingly, school meals provide a unique and rich source of nutrition for youth and may offset risk for overweight and obesity through mitigating food insecurity [9]. Children who are food insecure are at increased risk for obesity and diabetes $[10,11]$, two of the most common comorbidities associated with COVID-19 hospitalizations [12]. Before the pandemic, one in three children and adolescents were diagnosed with overweight or obesity [13]; current school closures could exacerbate risk of obesity in childhood and increase disparities [14]. Ensuring the continuity of school meal programs during a national emergency [15] is critical.

In response to school closures and the ensuing threat of child food insecurity, US Congress authorized support for school meal providers in COVID-19 federal relief packages in March of 2020. The United States Department of Agriculture (USDA) responded by granting nationwide waivers allowing school districts to (1) provide grab-and-go and home-delivered meals [16], (2) expand the hours when they serve food [17], (3) deviate from nutrition standards in the case of a supply chain disruption [18], and (4) allow guardians to pick up meals without children present [19]. The agency also waived the "area eligibility" requirement for the Summer Food Service Program (SFSP)/Seamless Summer Option (SSO) for states including California [20], Illinois [21], New York [22], and Texas [23], enabling districts to serve meals to low-income students where poverty was not as concentrated. Under normal circumstances, USDA only allows such meal provision where more than $50 \%$ of students qualify for free or reduced-price meals. With these waivers properly implemented, large urban school districts were in a position to effectively distribute emergency meals given that their operations already required 
complex food distribution, communication, and technology systems, and economies of scale can drive down costs in higher density populations. However, large urban districts typically serve predominantly ethnically, economically diverse populations in dense geographic areas. This creates distinct challenges given current social distancing recommendations.

Access is an important factor in establishing healthy dietary patterns. Lower income and racial/ethnic minority children, who are more likely to live in areas with limited food access, may be particularly vulnerable to changes in access during disasters, including the COVID-19 pandemic. An equitable emergency school meal system considers critical factors including availability (adequacy of the healthy food supply), accessibility (location and ease of getting to the food supply), affordability (food prices and perceptions of worth relative to cost), acceptability (attitudes about attributes of the food environment), and accommodation (how well local food sources accept and adapt to residents' needs) [24]. There is limited research of these factors when schools are closed - during emergencies or during summer meal service - and more research is therefore needed. Furthermore, the pressure on schools to re-open in the fall of 2020 is increasing, adding to the precarious state of school nutrition programs and meal service during the pandemic. Data regarding how school districts implemented emergency school meal programming will provide a better understanding of "gaps in the food safety net" [25] and help address areas for future improvement for schools as they consider reopening or continuing their emergency food service programming. Accordingly, we sought to address two aims in this case study:

1. Investigate the emergency school meal service strategies adopted by four of the largest school districts in the USA at the beginning of the COVID-19 pandemic.

2. Evaluate the degree to which districts promoted equitable access to emergency nutrition programming during the pandemic through a health equity lens.

\section{Methods}

This case study focused on four of the largest urban school districts in the USA [26]: Chicago Public
Schools (CPS), Houston Independent School District (HISD), Los Angeles Unified School District (LAUSD), and New York City Department of Education (NYCDOE). These sites were selected based on (1) location of the investigators' institutions (NYCDOE), (2) size of the school district (CPS, LAUSD, and NYCDOE are the three largest districts in the country), and (3) seeking district case sites from diverse geographic locations (Northeast, Midwest, West, South) in the USA. Furthermore, our ongoing collaboration with the Urban School Food Alliance yielded information that Houston was undergoing a reconstruction of their emergency school food response, warranting further study and investigation. Table 1 illustrates the demographic characteristics of these case study sites.

\section{Development of Guidelines for Equitable Meal Distribution}

To direct our assessment of each school district's meal distribution system, we developed an evidence-based set of guidelines for establishing an equitable emergency meal distribution system during a pandemic. Since the onset of COVID-19 in the USA, entities such as No Kid Hungry [27, 28] have published information on best practices for providing meal service during school closures. Furthermore, prior research on how emergency food supplies are deployed to address food insecurity during natural disasters $[29,30]$ offers insight into this important issue. To our knowledge, there are no guidelines for evaluating equity in an emergency meal distribution system during a pandemic. We endeavored to address this need by developing guidelines that can inform future actions of urban school districts.

This study was grounded in the Getting to Equity (GTE) in Obesity Prevention theoretical framework to inform guideline development [31]. The GTE framework was designed to provide practitioners and researchers with strategies to increase the equity impact of policy, system, and environmental (PSE) change interventions that aim to decrease obesity. The framework identifies opportunities for four key opportunities for intervention and action research that emphasize equity: (1) increase healthy options (e.g., increase access to healthy food retailers), (2) reduce deterrents (e.g., address threats to personal safety), (3) improve social and economic resources (e.g., offer nutrition assistance programs), and (4) build on community capacity (e.g., build strategic partnerships). Using the GTE framework [32], 
Table 1 District-level demographic data

\begin{tabular}{|c|c|c|c|c|}
\hline Variable & Chicago & Houston & Los Angeles & New York City \\
\hline No. of public schools (charter schools) & 642 (118 charter) & 280 (19 charter) & 1386 (288 charter) & 1866 (260 charter) \\
\hline K-12 public school enrollment & 337,664 & 209,772 & 557,560 & $1,126,501$ \\
\hline Percent of FARM students & $76.4 \%$ & $74.9 \%$ & $80 \%$ & $72.8 \%$ \\
\hline English learners (EL) & $18.8 \%$ & N/A & $22.2 \%$ & $13.2 \%$ \\
\hline African American & $35.9 \%$ & $24.0 \%$ & $8.2 \%$ & $25.5 \%$ \\
\hline Asian & $4.2 \%$ & $4.1 \%$ & $4.2 \%$ & $16.2 \%$ \\
\hline Hawaiian/Pacific Islander & $0.2 \%$ & N/A & $2.1 \%$ & NA \\
\hline Hispanic & $46.6 \%$ & $61.8 \%$ & $73.4 \%$ & $40.6 \%$ \\
\hline Multi-racial & $1.3 \%$ & NA & NA & NA \\
\hline Native American/Alaskan & $0.3 \%$ & NA & $<1 \%$ & NA \\
\hline White & $10.8 \%$ & $8.7 \%$ & $10.5 \%$ & $15.1 \%$ \\
\hline Not available & $0.7 \%$ & NA & $1 \%$ & NA \\
\hline
\end{tabular}

All data derived from publicly available school district data

$N A$, not available

relevant scientific literature [4, 33-38], and information from various health-focused organizations (e.g., No Kid Hungry, Feeding America, CDC, FDA) [27, 28, 30, 39], we drafted evidence-based guidelines for increasing the equity impact of an emergency meal distribution system during a pandemic. Guidelines were organized into four areas of action, similarly to the GTE framework (see Fig. 1), and were used to direct a detailed evaluation of documents and media that describe each school district's meal distribution strategies.

For the increasing healthy options domain, it was important to understand how meals were being distributed and promoted as a means to facilitate participation $[34,35]$, providing information on menu items and prioritizing healthy foods as an integral part of service [4], and providing as many meals as possible/feasible
Fig. 1 Getting to Equity framework adapted from Kumanyika 2019 [32] and grounded in literature and best practices on summer meal service and service during the COVID-19 pandemic. Text in each box indicates potential examples of emergency meal service attributes, (not exhaustive) for emergency school meals provision during the COVID-19 pandemic.

\section{Emergency school meals provision during COVID-19}

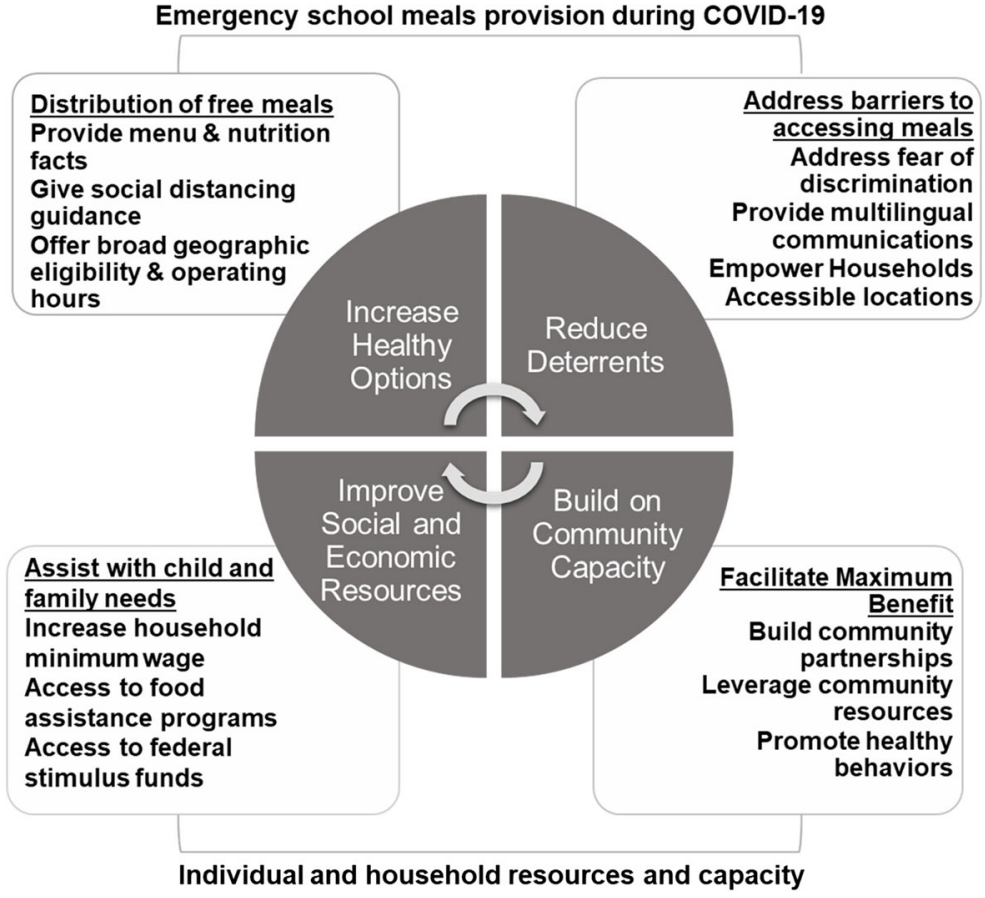


per collection period (i.e., breakfast and lunch, several days of food) [39]. Further, ensuring health and safety of children, families, and food service staff is an important component to maintaining access to emergency school meals $[34,40]$. In relation to reducing deterrents, literature and guidance points to the need to address barriers to accessing meals such as discrimination/stigma, language barriers, and safe access [33-35, 41]. As such, we were interested in the degree to which districts empowered children and families through inclusivity and attempted to reduce fears of discrimination through communication and outreach. The third quadrant, building on community capacity, was of particular interest, and through consultation of the literature, we sought to understand how districts collaborated with other organizations and networks to facilitate reach to children and families and promoted emergency school meals through these networks [27, 34, 35, 38].

Finally, we sought to understand how social and economic resources may be leveraged to facilitate access to school meals for those in greater need, such as provision of financial and logistical support to families $[34,42]$. High poverty is linked with greater food insecurity [25, 42], thus providing greater resources to families may help offset other costs, potentially mitigating the effect of COVID-19 on food insecurity. We recognize that the SSO and SFSP initiatives are developed with the sole purpose to offset food insecurity and thus are grounded following a health equity approach. The COVID-19 pandemic has presented additional challenges, however, which warrant further study and thus our findings can be used to inform current and ongoing meal distribution during the pandemic.

\section{Document Analysis}

For this evaluation, we completed a comprehensive document analysis to characterize each district's emergency meal distribution system and to identify promotion strategies. We gathered information about emergency meal provision practices from each district website and social media pages, including press releases, food service policies and guidance, meal site information, and images between mid-March and mid-May 2020. Through such a process, we also were able to gather the number of meals served by each district over this time period. All documents were stored in a shared Google Drive folder to facilitate open coding.
To capture overarching themes from documents and images, initial analysis was inductive, which allowed us to develop emergent open codes that were overarching concepts related to emergency school meal service [43]. Four members of the research team open-coded school districts' documentation separately and then met as a team to review open codes and discuss convergence/divergence. We then agreed upon an iterative coding strategy where one member led the initial document analysis and three members provided thorough member checking.

Using open coding, four research team members independently identified health and nutrition information for each school district's documentation. Based on this independent document analysis of all four urban school districts, a research team member developed a list of 25 open codes across the four domains of the GTE framework. Then, team members met to review all open codes and all school district documentation and reviewed and revised this list of codes [32, 44]. This list was finalized to 16 codes among the four domains (see Table 3). This iterative, team-based process facilitated a nuanced understanding of the factors that may impact emergency school meal service, and the degree to which district-level strategies could ensure equitable access to school meals. This approach enhanced integrity of the coding process but facilitated clear synergies to be identified to GTE framework.

\section{Geospatial Analysis of Meal Site Locations}

The aim of the geospatial analysis was to understand the availability and accessibility of meal sites by census tracts. We reviewed school district homepages for COVID-19-related district location information. All districts included dynamic, searchable data on meal sites on one of these two pages. Three districts included a link to a publicly available, interactive online map (LAUSD, HISD, CPS) and one (NYCDOE) included a drop-down menu of site locations. We used Python code to download publicly available data (e.g., site name, address, hours of operation) from each district daily between 14 April and 18 April 2020. Meal site locations were triangulated using district documentation (e.g., press releases).

For the spatial analyses, we either transferred meal site locations from mapped datasets or processed address information with the Google Maps application programming interface (API) through the BatchGeo website and geocoded sites (mapped location from a 
Table 2 School food service strategies by district

\begin{tabular}{lllll}
\hline & Chicago & Houston & Los Angeles & New York City \\
\hline Number of sites & $276+$ & $25+$ & 63 & $439+$ \\
Number of meals & 3 days of breakfast and lunch & $\sim 30$-pound food boxes & Breakfast and lunch & Breakfast, lunch, dinner \\
Pick-up times & $9: 00$ a.m.-1:00 p.m. & Times vary by location & $8: 00$ a.m.-11:00 a.m. & $7: 30$ a.m.-11:30 a.m. \\
Days of the week & M-F & M-Sat & M-F & M-F \\
\hline
\end{tabular}

physical address) to the highest level of positional accuracy possible. We decided to use food deserts as an important metric of food access because children living in these areas may have greater problems accessing healthier foods compared with non-food desert dwellers, and have a greater need for access to safety net programs like school meal programs in order to meet dietary recommendations. We joined the USDA Food Desert Locator dataset to a census tract boundary map file for food desert data. USDA defines "food deserts" in urban areas as low-income census tracts where a significant number or share of residents is more than $1 / 2$ mile from the nearest supermarket [45]. We joined the food desert polygon data to meal site location point data.

To identify meal sites relative to high poverty areas, racial minorities, and youth population (age 5-19), we used the American Community Survey, 2014-2018, 5year estimates at the Census tract level. We extracted Census tract-level variables of "percent minority" (all non-White, including Hispanic) and "percent poverty level" (income in the past 12 months below poverty level, divided by total households) and joined these data to census tract boundary map files. We extracted the total population of children ages 5-19 in each census tract and used school district boundary files to select only the census tracts that fell within the school district perimeter. We joined the census sociodemographic data to the meal site location data and determined the number of meal sites per census tract. Finally, we used univariate statistics to determine the prevalence (count and proportion) of meal sites in census tracts above and below the median census tract measure for each characteristic described above (i.e., percent poverty, percent racial/ ethnic minority, population 5-19 years of age).

\section{Results}

Normally, CPS serves around 390,000 meals a day [46]. In April, the district served between 230,000 and
320,000 meals a day (59-82\% of typical service). For the week of 13th April, the same week used for GIS data collection, LAUSD served between 427,000 and 585,000 [47] (61-83\% of typical service), and NYCDOE served between 158,000 and 270,000 meals to children per day (19-32\% of typical numbers) from its food "hubs." HISD, which typically serves 250,000 meals a week [48], distributed between 60,000 and 75,000 pounds a week in food boxes [49].

\section{Aim 1: School Food Service Strategies}

After piloting different service concepts and strategies before spring break, all districts committed to models that remained the rest of the scheduled school year (see Table 2). A visual representation of availability and accessibility for NYCDOE can be found in Fig. $2 .{ }^{1}$ Site distribution across cities varied, with two distinct strategies emerging. HISD and LAUSD operated fewer overall sites, but appeared to strategically place central collection points throughout the district. NYCDOE and CPS emphasized more sites and more localized coverage across district areas. For example, in the first weeks of school closure, CPS served 3 days' worth of breakfast and lunches from all 642 schools [50]. During spring break, CPS provided grab-and-go meals from 136 school sites. Starting April 13th, the district consolidated food service at the 276 schools with the highest participation before spring break. Families could pick up 3 days' worth of meals every weekday from 9:00 a.m. to $1: 00$ p.m. [51].

HISD originally distributed meals from 36 school sites in partnership with the Houston Food Bank School Market Program [52] but halted operations when staff were exposed to COVID-19 [53]. The district

\footnotetext{
${ }^{1}$ Additional maps for CPS, HISD, and LAUSD can be found in an online appendix (https://wustl.box.com/s/z4bs5saixs $5 \mathrm{rm} 2 \mathrm{k} 7 \mathrm{z} 1$ yjkfrmsh4qdlug).
} 

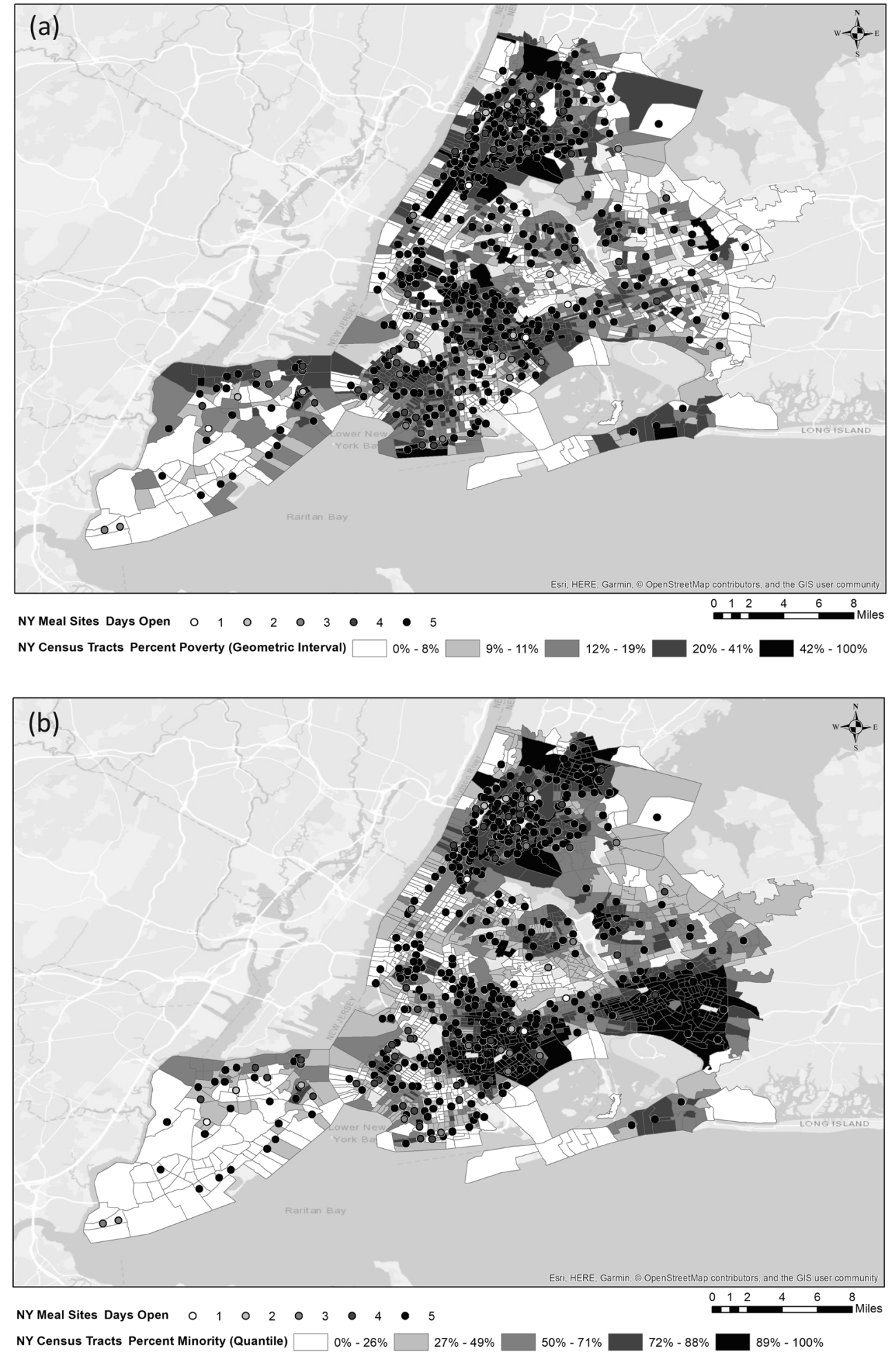

Fig. 2 New York Public School District Meal Distribution and Census Tracts characteristics: a percent poverty, b percent minority, c school age population, and $\mathbf{d}$ prevalence of food deserts ( $1 / 2$ mile). Additional maps for Chicago, Houston, and Los Angeles can be found in an online appendix (https://wustl.box.com/s/z4bs5saixs5rm2k7z1yjkfrmsh4qdlug) 

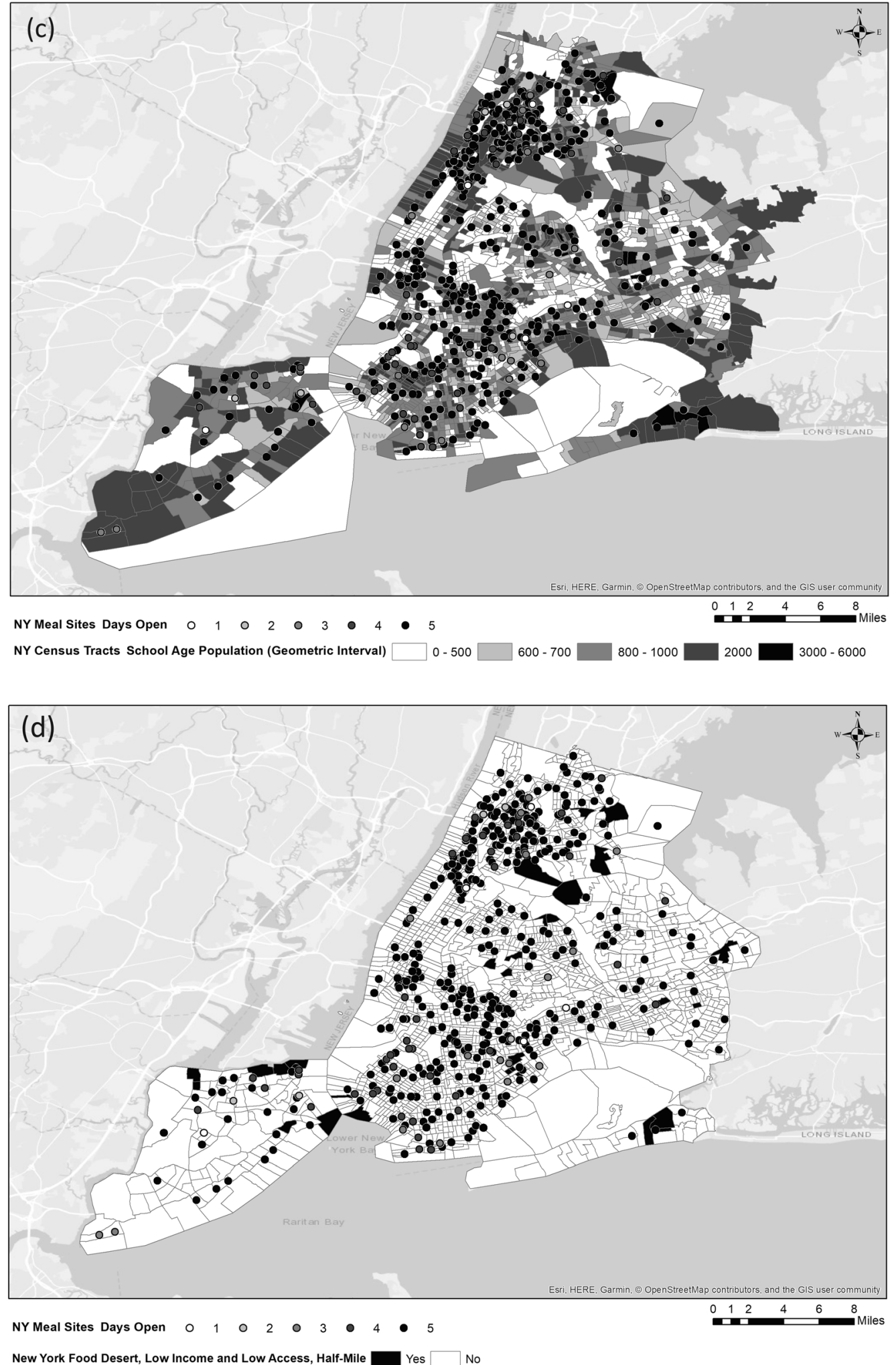

Fig. 2 continued. 
relaunched food service on April 6th, after spring break, distributing 30-pound boxes of food [54] instead of meals. HISD continued to distribute 500 boxes, daily (including weekends), from four to five locations across the city, depending on the day of the week [49]. Distribution times varied from morning to afternoon, depending on the site.

LAUSD initially proposed opening 40 Family Resource Centers where children could study and obtain warm meals [55], but abandoned the plan before implementation. Instead, on 18th March, the district announced 60 grab-and-go food centers, open Monday through Friday from 7:00 a.m. to 10:00 a.m. [56]. (As of 6th April, centers were open from 8:00 a.m. to 11:00 a.m.). Working with the Red Cross, volunteers, and school food staff, LAUSD provided breakfast and lunch to families at pick-up sites.

For the first week of school closures in New York (16-20 March 2020), NYCDOE provided grab-and-go breakfast and lunches from each of its 1800 plus schools. The following week, starting 23rd March, NYCDOCE began providing students grab-and-go breakfast, lunch, and dinner Monday through Friday from 7:30 a.m. to 1:30 p.m. outside 439 schools deemed citywide "hubs." The district continued to provide hot meals at "Regional Enrichment Centers" for children of essential workers [57] and launched a partnership with DoorDash to deliver tailored meals to medically vulnerable students [58]. NYCDOE temporarily closed sites for cleaning when staff fell sick and permanently shuttered others due to low participation. However, the general trend was to open more service locations; NYCDOE operated approximately 500 sites at the beginning of May.

\section{Aim 2: Analysis through a Health Equity Lens}

According to the GTE framework, the two domains for increasing health equity through policy and systems change interventions are: "Increase Healthy Options" and "Reduce Deterrents" to health promotion and healthy behaviors [32]. The two key domains for building individual, household, and community resources and capacity are: "Increase Social and Economic Resources" and "Build Community Capacity." Our findings for urban school districts' responses to the COVID19 pandemic appear in Table 3 matched to the GTE framework and are depicted in an adapted GTE framework in Fig. 1 [32].
Increase Healthy Options: Distribute School Meals

Districts' efforts to increase healthy options during the COVID-19 pandemic varied by addressing barriers to accessing meals; offering a breadth of geographic eligibility and distribution of free meals, the number and quality of meals offered, and choices to serve children and adults; emphasized "healthy, nutritious" meals; and providing menus and nutrition information. Each district took advantage of federal waivers to offer free meals during school closures: CPS and LAUSD offered two free meals, and NYCDOE offered three free meals a day. In contrast, HISD offered a bag of free groceries a week, with no apparent limit on site visits for families.

All districts specified that food was available to students, but only three of the four used language that made it clear adults could also pick up food. For example, when still providing grab-and-go meals, HISD restricted the program to adults with children present and did not provide menus for the food boxes. All districts offered social distancing guidelines, but LAUSD and NYCDOE emphasized the topic with specific reference to social distancing and wearing masks, specifically for staff.

\section{Reduce Deterrents: Address Barriers to Accessing Meals}

To reduce deterrents to health promotion and health behaviors during the COVID-19 pandemic, districts provided grab-and-go meal locators and maps, up-todate information on site closures and the number of active sites, links to partner sites (i.e., food banks), and meal options for special or restricted diets (e.g., religious restrictions), as a proxy for addressing the fear of discrimination. For example, HISD partnered with Houston Food Bank to distribute meals from convenient community locations, and LAUSD offered free meal distribution at homeless shelters. While NYCDOE promoted Kosher, Halal, and vegetarian options, HISD was the only district that did not offer special or restricted diet options; CPS did not list partner sites or offer vegetarian and gluten-free options. One important distinction to draw from Houston's approach to meal service is that, providing large boxes of food (i.e., 30 pounds) may present a barrier/deterrent for individuals seeking emergency nutrition, particularly if they do not have access to a car or other convenient transportation. 
Table 3 Document analysis results for urban school districts

\begin{tabular}{|c|c|c|c|c|}
\hline GTE framework themes & Chicago & Houston $^{\mathrm{a}}$ & Los Angeles & New York City \\
\hline \multicolumn{5}{|l|}{ Increase healthy options } \\
\hline Distribute free meals ${ }^{\mathrm{b}}$ & $\checkmark \checkmark$ & $\checkmark$ & $\checkmark \checkmark$ & $\checkmark \checkmark \checkmark$ \\
\hline Provide menu and nutrition information & & $\checkmark$ & & $\checkmark$ \\
\hline Give social distancing guidance & $\checkmark$ & $\checkmark$ & $\checkmark$ & $\checkmark$ \\
\hline Offer broad geographic eligibility & $\checkmark$ & & $\checkmark$ & $\checkmark$ \\
\hline \multicolumn{5}{|l|}{ Reduce deterrents } \\
\hline Address barriers to accessing meals & $\checkmark$ & $\checkmark$ & $\checkmark$ & $\checkmark$ \\
\hline Offer accessible locations ${ }^{c}$ & $\checkmark$ & $\checkmark$ & $\checkmark$ & $\checkmark$ \\
\hline Address fear of discrimination ${ }^{\mathrm{d}}$ & $\checkmark$ & & $\checkmark$ & $\checkmark$ \\
\hline Provide multilingual communications ${ }^{\mathrm{e}}$ & & $\checkmark$ & $\checkmark$ & $\checkmark$ \\
\hline Empower households ${ }^{\mathrm{f}}$ & $\checkmark \checkmark$ & $\checkmark$ & $\checkmark \checkmark$ & $\checkmark \checkmark$ \\
\hline \multicolumn{5}{|l|}{ Build on community capacity } \\
\hline Build community partnerships & $\checkmark$ & $\checkmark$ & $\checkmark$ & $\checkmark$ \\
\hline Leverage of community resources & $\checkmark$ & $\checkmark$ & $\checkmark$ & $\checkmark$ \\
\hline Promote healthy behaviors & $\checkmark$ & $\checkmark$ & $\checkmark$ & $\checkmark$ \\
\hline \multicolumn{5}{|l|}{ Improve social and economic resources } \\
\hline Assist with child and family needs & $\checkmark$ & $\checkmark$ & $\checkmark \checkmark$ & $\checkmark \checkmark$ \\
\hline Access to food assistance programs & $\checkmark$ & $\checkmark$ & $\checkmark$ & $\checkmark$ \\
\hline Access to federal stimulus funds & $\checkmark$ & $\checkmark$ & $\checkmark$ & $\checkmark$ \\
\hline Increase household minimum wage & $\checkmark$ & & $\checkmark$ & $\checkmark$ \\
\hline
\end{tabular}

${ }^{\mathrm{a}}$ Food-bank-style distribution initially, then providing lunch and a snack early in March, community sites for food distribution and school meals after

${ }^{\mathrm{b}}$ Check marks indicate number of free meals provided: $\checkmark \checkmark$ two free meals per day; $\checkmark \checkmark \checkmark$ three free meals per day

${ }^{\mathrm{c}}$ Grab-and-go or meal distribution sites

${ }^{\mathrm{d}}$ By accommodating special diets

${ }^{\mathrm{e}}$ One language in Chicago, three languages in Houston, two languages in LA, and eleven languages in NYC

${ }^{\mathrm{f}}$ Empower households is a summary measure that includes an overall score of each city, based on the other quadrants

Providing multilingual information and resources was another way district leadership reduced deterrents for the inclusivity of diverse households; again, CPS was the exception. HISD offered resources and educational materials in Spanish and English; LAUSD in Spanish, Vietnamese, and English; and NYCDOE in Arabic, Bengali, Chinese, English, French, Haitian, Creole, Korean, Russian, Spanish, and Urdu (11 languages). Between 14 April and 18 April, the four districts had between 26 and 447 meal sites open daily. Figure 2 illustrates geographic depictions of meal site locations across NYCDOE, distributed across census tracts coded for each variable of interest. ${ }^{2}$ Table 4 shows the distribution of meal sites in each district above and

\footnotetext{
${ }^{2}$ Additional maps for CPS, HISD, and LAUSD can be found in an online appendix (https://wustl.box.com/s/z4bs5saixs5rm2k7z1 yjkfrmsh4qdlug).
}

below the median census tract measure for each variable of interest. Meal sites appeared to be in areas with highminority populations, except for CPS. Districts also appeared to place most meal sites in areas above the median poverty level. HISD had the greatest percentage $(68 \%)$ of sites in areas of higher poverty, and NYCDOE had the greatest number $(301 ; 67 \%)$. The maps reflect the trends in Table 4, except for HISD and NYCDOE. In HISD, only one high poverty area (51.9\% and above) contained a meal site, and in NYCDOE, a considerable number of high poverty tracts did not have meal sites.

Images on school district documents and social media platforms that evoked equity and empowerment were another strategy to reduce deterrents. LAUSD used cheerful cartoon images of ethnically diverse children dressed in colorful clothes holding fruits and vegetables. NYCDOE displayed smiling children of diverse 
Table 4 School district meal site distribution above and below district median census tract demographics (percent minority, percent poverty, median population $\leq 19$ years old)

\begin{tabular}{|c|c|c|c|c|}
\hline & LAUSD $(n$ of sites $=63)$ & HISD $(n=26)$ & $\operatorname{NYCDOE}(n=447)$ & CPS $(n=297)$ \\
\hline Median percent minority ${ }^{\mathrm{a}}$ & $46.7 \%^{\mathrm{a}}$ & $36.0 \%{ }^{\mathrm{a}}$ & $59.0 \%{ }^{\mathrm{a}}$ & $46.8 \%{ }^{\mathrm{a}}$ \\
\hline Below median & $22(35 \%)$ & $6(24 \%)$ & $179(40 \%)$ & $181(60 \%)$ \\
\hline Above median & $41(65 \%)$ & $19(76 \%)$ & $268(60 \%)$ & $119(40 \%)$ \\
\hline Median $\%$ poverty $^{\mathrm{a}}$ & $16.3 \%^{\mathrm{a}}$ & $19.6 \%{ }^{\mathrm{a}}$ & $14.4 \%^{\mathrm{a}}$ & $18.1 \%^{\mathrm{a}}$ \\
\hline Below median & $21(33 \%)$ & $8(32 \%)$ & $146(33 \%)$ & $113(38 \%)$ \\
\hline Above median & $42(67 \%)$ & $17(68 \%)$ & $301(67 \%)$ & $187(62 \%)$ \\
\hline Median population 5-19 years old ${ }^{\mathrm{a}}$ & $920^{\mathrm{a}}$ & $1121^{\mathrm{a}}$ & $779^{\mathrm{a}}$ & $727^{\mathrm{a}}$ \\
\hline Below median & $23(37 \%)$ & $12(48 \%)$ & $151(34 \%)$ & $88(29 \%)$ \\
\hline Above median & $40(63 \%)$ & $13(52 \%)$ & $296(66 \%)$ & $212(71 \%)$ \\
\hline \multicolumn{5}{|l|}{ Food desert classification $^{\mathrm{a}}$} \\
\hline Meal sites in food desert ( $1 / 2$ mile $)$ & $21(33.3 \%)$ & $21(80.7 \%)$ & $5(1.1 \%)$ & $87(29.2 \%)$ \\
\hline Meal sites in non-food desert & $42(66.6 \%)$ & $4(19.3 \%)$ & $442(98.9 \%)$ & $211(71.8 \%)$ \\
\hline
\end{tabular}

Cells represent count and (percent) of total meal sites either above or below the district median

Note: $n$, number of meal sites per district

${ }^{\text {a }}$ Corresponding median measure for each district

ethnicities playing outside. CPS' and HISD's images did not promote as much diversity in comparison (e.g., photos of children eating at a table close to each other and children drinking milk from cartons).

All districts employed varying degrees of health equity and empowerment language. CPS stated that "everyone deserves to lead a healthy life" [50]; HISD emphasized the importance of "nutritional services mobilizing food safely" [49]; LAUSD called attention to an "outpouring of community support"; and NYCDOE stressed "commitment to health and safety." Districts also employed empathetic language to acknowledge families' hardship during the pandemic. LAUSD used explicit phrases like "support families in need" [56] and New York devoted a webpage to "messages to families," which included memos from the Mayor discussing the difficult time, the need to "come together," and that "no one can be turned away" [59]. Together, these districts' images and language indicate a concerted effort to promote diversity and inclusion in communication.

\section{Build on Community Capacity: Facilitate Maximum} Benefit

Districts built on community capacity by building community partnerships [e.g., establishing programs to support first responders and their families, fundraising, partnering with community-based organizations, and distributing staple foods (HISD only)]. HISD partnered with the regional food bank and the police department to distribute free food in communities. In addition, LAUSD partnered with the Red Cross to help distribute meals, and promoted a list of local wellness centers/school clinics available on the resources website to enhance awareness of children/ families. NYCDOE also provided information on local community resources, such as Regional Enrichment Centers which were available specifically for children of first responders, healthcare workers, and vulnerable populations. CPS also took this initiative and provided resources for parents who worked as first responders pertaining to childcare and emergency nutrition opportunities.

All districts promoted healthy behaviors by placing a majority of meal sites in tracts with above-median juvenile populations. CPS placed the highest proportion of meal sites in these areas $(n=212,71 \%)$, whereas HISD had the lowest proportion with $13(53 \%)$ of their meal sites in census tracts above median juvenile population. Placement of these sites has implications for reach and participation in emergency school food service programming.

Increase Social and Economic Resources: Assist with Child and Family Needs

Urban school districts offered a wide range of resources for families impacted by COVID-19, beyond nutritional 
supplementation. All clearly communicated weekday hours to access free meals, promoting visibility of the school meal programming. HISD also offered weekend hours for adults and NYC provided afternoon hours for adults who needed food. Further, all school districts provided access to wellness programs or centers; wellness resources can reduce deterrents such as discrimination and social exclusion [32]. Moreover, although indirectly related to food service, all districts provided technology, such as iPads and Chromebooks to students to facilitate distance learning, in addition to $\mathrm{Wi}-\mathrm{Fi}$ through partnerships with local/national companies. This may therefore offset financial barriers experienced by families in the COVID-19 pandemic and increase their ability to access up-to-date information about meal sites. In USDA- defined food deserts, HISD placed the greatest proportion of meal sites $(n=21,80.7 \%)$, whereas NYCDOE placed only five meal sites (1.1\%). Meanwhile, both CPS and LAUSD placed roughly a third of sites in food deserts. Finally, other considerations for all school districts in light of global crises such as COVID19 are local policies and programs that can increase resources to low-income households, beyond the school system. These include the federal stimulus plan, access to food assistance programs, and local efforts such as raising the minimum wage.

\section{Discussion}

Using an innovative mixed methods approach, this study investigated approaches to COVID-19 pandemic school meal service among four of the nation's largest urban school districts, and how strategies could ensure equitable access to supplemental nutrition during the pandemic. Nutrition assistance programs such as NSLP and SBP can reduce food insecurity and help prevent child obesity [10]. Understanding strategies to assure program access during emergencies is critical to promoting equity.

In relation to increasing healthy options, districts used multiple strategies to encourage participation, but meals reached only a portion of the normal student population. There were no clear patterns to suggest whether the number or kinds of meals served, location and number of distribution sites, or time of day affected participation. NYCDOE had the lowest average participation rate, which may have more to do with COVID19 prevalence and larger structural barriers (a factor for future study), than with specific distribution practices, or both. Moreover, it was the largest district and the most difficult to navigate without public transport compared with LAUSD or HISD where cars are more common. It is important to consider the nuanced challenges presented in the COVID-19 pandemic that may have previously been considered as strengths, such as predominant use of public transport and dense populations of urban context.

Notably, all districts deviated from initial distribution plans, suggesting that districts have much to learn when it comes to meal distribution during school closures. All districts took steps to increase access to healthy options; they provided at least one meal per day for students, displayed food safety information, and advertised that all children could eat for free regardless of district enrollment. But there were differences in the number of free meals provided, populations served, and communication about menu options. During school closures, not all districts published menus, making nutritional quality of foods unclear. These differences may impact food security, given strong reliance on school food programs in urban contexts [4].

To reduce deterrents to participating in emergency school meal programs, hunger and nutrition advocacy groups encourage districts to provide multiple days' meals, serve adults, and post menu information. Given the strong links between food insecurity and child/ adolescent obesity $[10,11,60]$, the importance of school meal nutritional quality cannot be understated. It is highly likely that some form of emergency meal service likely to continue in the 2020-2021 school year and districts should strive to provide nutritional information and promote consumption of high-quality foods. Districts should also strive to provide more information in multiple languages representing all the relevant cultures and nationalities to reduce deterrents to health, particularly fear of discrimination and other inequities confronted by diverse households. All districts provided interactive maps to display meal locations and hours, potentially making it easier for families to access school meals.

In regard to building community capacity and improving social and economic resources, all districts had some form of building community partnerships including collaborating with first responder programs and promoting relief fundraisers. Developing an inclusive community culture and partnerships are methods national anti-hunger organizations such as Share Our Strength 
No Kid Hungry campaign [27] recommend to improve meal distribution and ensure equitable access to nutrition. Partnerships not only build community capacity, they can also help improve social and economic resources. For example, HISD's partnership with Houston Food Bank facilitated weekend meals and outreach efforts to families. Weekend meals can increase children's and families' food security [61]. Given the economic crisis that resulted from the pandemic, additional weekend meals may be a more important factor than ever. Moreover, due to the significant economic crises of the COVID-19 pandemic, it would also be essential for researchers to consider factors beyond the school system, such as equitable access to federal stimulus checks and local policies to aid low-income households through raising the minimum wage, for instance. Further research is needed to understand how these macro-level factors may play a greater role in health equity in the coming months, particularly as schools begin to re-open and changes to emergency meal distribution manifest.

Although our study is the first to look at the spatial distribution of pandemic school meal site locations in large urban areas during the COVID-19 pandemic, our results could be interpreted in the context of previous work examining meal site placement during school closures. One previous study examined the placement of summer meal sites [25] and found that urban summer meal sites were more prevalent in larger, higher poverty, and majority non-White high schools. We found similar patterns during the response COVID-19 pandemic, with more sites in the larger, higher poverty and higher minority areas. Unlike summer meal sites, which are required to operate in low-income areas, where at least half of resident families' income falls below $185 \%$ of the federal poverty level [62], meal sites opened and operated during the COVID-19 pandemic were not required to meet this same criterion. In this case, we did expect to see some level of variation in meal sites across census tract income levels, compared with the placement of summer sites.

Meal site placement that remained consistent with placing sites in areas with higher economic need is promising and could be, at least partially, based on a site or school's previous experience as a summer meal site. Future research should include evaluations of how districts used these variables of interest or other equitybased considerations in their decisions concerning meal site locations during COVID-19, especially as areas of high poverty appeared to be the most consistently prioritized across the four cities. Such an approach for future studies could be based on the idea that lowincome populations often have lower access to healthy foods, which is supported by previous research [63]. With regard to food access, we found that sites were more equitably distributed based on demographic characteristics rather than food desert status. Focusing on demographic rather than food environment characteristics could leave children living in food deserts without adequate access to healthy food, so further consideration should be given to food assistance and food access data. In this research, we focused on the availability of meals sites, but other dimensions of food access may be influential [24] and should be examined in future studies.

\section{Strengths and Limitations}

This study uses a novel equity framework to classify elements of intervention design, delivery, and contextual factors influencing provision of emergency healthy meals during unplanned school closures. These districts represent multiple regions of the country: The East Coast (NYCDOE), Midwest (CPS), South (HISD), and West Coast (LAUSD). This study also employs a rigorous mixed methodology for document analysis and geo-spatial mapping. It analyzes school districts' efforts while the USA is in the midst of an unprecedented pandemic. Our findings are currently relevant for school meal and other nutrition assistance providers given the persistent threat of COVID-19. Congress has mandated that states submit a report to USDA describing districts' use of school meal waivers 1 year after this emergency. Paired with state reports, this study can inform future plans for public health emergencies and accelerate the implementation of school meal service.

We must also acknowledge some limitations of this study. Recommendations to social distance and the time constraints the public health emergency created for school meal providers limited data collection. We relied completely on publicly available data such as websites and social media, and did not recruit participants for primary data collection to avoid burdening food service management and other school staff and stakeholders during such a critical time. Although we collected information over a prolonged period (i.e., 6 weeks), we plan to conduct follow-up research in collaboration with other research teams to identify the ways in which school districts approached their emergency school 
meal programs and deviations from initial plans. Finally, although we chose urban districts in each major region of the USA, findings are not generalizable to other diverse urban districts. Instead, with the data available, we were able to identify and characterize each district's public efforts to provide meals during school closures.

\section{Future Directions}

This case study highlights salient challenges and successes within four urban communities, but more work is needed to address school food practices. While this study focused on urban areas, suburban and rural districts' responses also warrant study. There is also a need to understand the current use of geospatial data to determine the location of meal sites, how the location of sites changed over time, and what opportunities there are to better integrate such data to improve reach of emergency school meal programming. Future studies could also examine centralized versus more widespread site distribution; the way districts distributed sites suggests an intentional, although varying approach to address food access issues. Due to how meal distributions differed (i.e., number of meals per day and days of food), we could not establish whether more sites led to better reach. Therefore, it may be beneficial to study the differential impact on population accessibility to school meals, as well as the impact on pickup, district purchasing, and dietary patterns.

Our study focused on food deserts rather than other food environment conditions such as food swamps due to the potential exacerbation of food insecurity due to meal site location for vulnerable children living in areas of low access to healthy food, but the relation of meal sites to food swamps, particularly as a competition for school meal site usage, should be a focus of future work. Finally, and most importantly, additional work should be conducted to contextualize stakeholder perspectives on the distribution of meal sites, both from the perspectives of decision makers (i.e., those individuals or groups responsible for identifying meal site locations and approaches, developing and disseminating information about sites, and evaluating the relative success or failure of approaches) and of community members, program recipients, program collaborators, and decisionmakers (e.g., anti-hunger organizations, youth empowerment organizations, and local economic policymaking).
For urban school districts, one future direction may be to develop and maintain partnerships with community organizations to prevent food insecurity during school closures due not just to pandemics or natural disasters, but also weekend and holiday closures. Research suggests community organizations like food banks are valuable stakeholders in preventing food insecurity and insecurity-related chronic disease $[64,65]$, so sustained partnerships between these two entities may help reduce food insecurity.

As schools begin to reopen in the fall of 2020 following pressure from federal agencies [66], we strongly urge equity to be placed at the forefront of decisions pertaining to school emergency food services. Given the detrimental impact of COVID-19 on the economic landscape of the USA and subsequent surge in food insecurity prevalence [67], continuation of meal sites that serve meals to students and families may serve as a vital strategy to offset ongoing depravity. This will be especially important for families/children at a greater risk for contracting COVID19 who wish to remain at home and/or for parents who still cannot return to work through job loss or ongoing furlough. Further, depending on the school schedule and whether schools opt for a rotation system to minimize attendance and asking students to be at school on certain days of the week, continued operation of walk-up and drive-up meal sites would facilitate equitable access to supplemental nutrition despite students not attending schools full-time. Continuation of various waivers granted by the USDA may therefore be necessary to combat rising food insecurity rates and ease the transition of going back to school amid the pandemic.

\section{Conclusions}

The findings provide a unique perspective to promote equitable food access to students and families during a public health crisis. School meal, summer meal, and emergency food service providers can use the findings to promote participation, especially among nutritionally vulnerable populations. The need to address urban communities' food security challenges by providing equitable access to meals during a public health emergency cannot be understated, and our study is one of the first to address food security issues during COVID-19. Findings provide valuable insights for future meal provision both during public health emergencies and ongoing federal interventions to combat food insecurity in children and households. 
Acknowledgments We are grateful to both Healthy Eating Research, a national program of the Robert Wood Johnson Foundation, and the United States Department of Health and Human Services Centers for Disease Control and Prevention-supported Nutrition and Obesity Policy Research and Evaluation Network (NOPREN) for their support of an ad hoc joint COVID-19 School Implications Working Group and to NOPREN for fellowship support (GM, CD).

Funding All authors are members of the ad hoc COVID-19 School Nutrition Implications Working Group, jointly supported by Healthy Eating Research, a national program of the Robert Wood Johnson Foundation, and the Nutrition and Obesity Policy Research and Evaluation Network (NOPREN). NOPREN is supported by Cooperative Agreement No. 5U48DP00498-05 from the Centers for Disease Control and Prevention, Prevention Research Centers Program. GM and CD are supported through NOPREN fellowships. The findings in this report are solely the responsibility of the authors and do not necessarily represent the official views of the Healthy Eating Research, the Robert Wood Johnson Foundation, the Centers for Disease Control and Prevention, or Share Our Strength.

\section{References}

1. Gross SM, Kelley TL, Augustyn M, Wilson MJ, Bassarab K, Palmer A. Household food security status of families with children attending schools that participate in the community eligibility provision (CEP) and those with children attending schools that are CEP-eligible, but not participating. J Hunger Environ Nutr. 2019:1-16. https://doi.org/10.1080 /19320248.2019.1679318.

2. Fletcher JM, Frisvold DE. The relationship between the school breakfast program and food insecurity. $J$ Consum Aff. 2017;51(3):481-500. https://doi.org/10.1111 /joca.12163.

3. United States Department of Agriculture. Food security in the US. https://www.ers.usda.gov/topics/food-nutritionassistance/food-security-in-the-us/. Accessed 8 July 2020.

4. Ralston K, Treen K, Coleman-Jensen A, Guthrie J. Children's Food Security and USDA Child Nutrition Programs. 2017. https://www.ers.usda.gov/publications/pubdetails/?pubid=84002. Accessed 20 May 2020.

5. Forrestal S, Cabili C, Dotter D, et al. School nutrition and meal cost study, final report volume 1: school meal program operations and school nutrition environments. https://fnsprod.azureedge.net/sites/default/files/resourcefiles/SNMCS-Volume1.pdf. Published 2019. Accessed 10 May 2020.

6. Story M, Nanney MS, Schwartz MB. Schools and obesity prevention: creating school environments and policies to promote healthy eating and physical activity. Milbank $Q$. 2009;87:71-100. https://doi.org/10.1111/j.14680009.2009.00548.x.

7. Au LE, Gurzo K, Gosliner W, Webb KL, Crawford PB, Ritchie LD. Eating school meals daily is associated with healthier dietary intakes: the healthy communities study. $J$
Acad Nutr Diet. 2018;118(8):1474-81. https://doi. org/10.1016/j.jand.2018.01.010.

8. Misyak S, Farris A, Mann G, Serrano E. Eat smart, move more in schools: a comprehensive program to improve the school food environment outside of the NSLP developed through a multi-state collaboration. J Nutr Educ Behav. 2017;49(7, Supplement 1):S13. https://doi.org/10.1016/j. jneb.2017.05.040.

9. Kenney EL, Barrett JL, Bleich SN, Ward ZJ, Cradock AL, Gortmaker SL. Impact of the healthy, hunger-free kids act on obesity trends. Health Aff. 2020;39(7):1122-9. https://doi. org/10.1377/hlthaff.2020.00133.

10. Kaur J, Lamb MM, Ogden CL. The association between food insecurity and obesity in children-the National Health and Nutrition Examination Survey. J Acad Nutr Diet. 2015;115:751-8. https://doi.org/10.1016/j. jand.2015.01.003.

11. Seligman HK, Bindman AB, Vittinghoff E, Kanaya AM, Kushel MB. Food insecurity is associated with diabetes mellitus: results from the National Health Examination and Nutrition Examination Survey (NHANES) 1999-2002. J Gen Intern Med. 2007;22:1018-23. https://doi.org/10.1007 /s11606-007-0192-6.

12. Richardson S, Hirsch JS, Narasimhan M, Crawford JM, McGinn T, Davidson KW, et al. Presenting characteristics, comorbidities, and outcomes among 5700 patients hospitalized with COVID-19 in the New York City area. JAMA. 2020;323:2052. https://doi.org/10.1001/jama.2020.6775.

13. Ogden CL, Carroll MD, Kit BK, Flegal KM. Prevalence of childhood and adult obesity in the United States, 2011-2012. JAMA J Am Med Assoc. 2014;311:806-14. https://doi. org/10.1001/jama.2014.732.

14. Rundle AG, Park Y, Herbstman JB, Kinsey EW, Wang YC. COVID-19-related school closings and risk of weight gain among children. Obesity. 2020;n/a(n/a). https://doi. org/10.1002/oby.22813

15. Food Security Information Network (FSIN). Global Report on Food Crises. Published 2019. https://www.fsinplatform. org/report/global-report-food-crises-2020/. Accessed June 20, 2020

16. United States Department of Agriculture. Nationwide waiver to allow non-congregate feeding in the child nutrition programs. https://www.google.com/url?q=https://fns-prod. azureedge.net/sites/default/files/resource-files/COVID19NonCongregateNationwideWaiver.pdf\&sa $=$ $\mathrm{D} \& \mathrm{ust}=1589812822102000 \& \mathrm{usg}=\mathrm{AFQjCNG} 7$ SPJbJYggAcVcDNkQCgg4YpTqQw. Published 2020. Accessed 11 May 2020.

17. United States Department of Agriculture. Nationwide waiver to allow meal service time flexibility in the child nutrition programs. https://www.google.com/url?q=https://fns-prod. azureedge.net/sites/default/files/resource-files/COVID19Mea $1 \mathrm{~T}$ i mes Nationwide Waiver.pdf \& s a = D\&ust=1589812822104000\&usg=AFQjCNGesJq3YBs 1 KhmcXxJSVarP16OTyw. Published 2020. Accessed 11 May 2020.

18. United States Department of Agriculture. Nationwide waiver to allow meal pattern flexibility in the child nutrition programs. https://www.google.com/url?q=https://fns-prod. azureedge.net/sites/default/files/media/file/COVID19 MealPatternNationwideWaiverFINAL.pdf\&sa= 
D\&ust $=1589812822105000 \&$ usg $=$ AFQjCNGCbxHd9 mPqPYE023v-Arqkjp1orw. Accessed 11 May 2020.

19. United States Department of Agriculture. Nationwide waiver to allow parents and guardians to pick up meals for children. March 25, 2020. https://www.google.com/url?q= h t t p s : / / f n s - p r o d a z u r e e d g e . net/sites/default/files/media/file/COVID 19 ParentPickupNationwideWaiver.pdf\&sa= $\mathrm{D} \& \mathrm{u} \mathrm{s} \mathrm{t}=1589812822106000 \& \mathrm{u} \mathrm{s} \mathrm{g}=$ AFQjCNEDJVohxyrgCP1sDmvZFjAhskn9Yw. Published 2020.

20. The United States Department of Agriculture. California area eligibility approval. March 30, 2020. https://www. google.com/url?q=https://fns-prod.azureedge. net/sites/default/files/resource-files/CA-CN-COVAreaE1igibility-Approva $1 . p d f \& s a=$ $\mathrm{D} \& \mathrm{ust}=1589812822107000 \& \mathrm{us} \mathrm{g}=$ AFQjCNGrBocrLivJlbrG_c8CgbWAdYJCfw. Published 2020. Accessed 11 May 2020.

21. United States Department of Agriculture. Illinois area eligibility approval. March 31, 2020. https://www.google. c o m/url? q=h t tps://fns - prod.azureedge. net/sites/default/files/resource-files/IL-CN-COVAreaEligibility-Approval.pdf \& s a = $\mathrm{D} \& \mathrm{ust}=1589812822108000$ \& u s g = AFQjCNFpYAXNlQug4xkvVwqHotGf8arS9Q. Published 2020. Accessed 11 May 2020.

22. United States Department of Agriculture. New York area eligibility approval. March 29, 2020. https://www.google. com/url? q = https ://fns-prod.azureedge. net/sites/default/files/resource-files/NY-CN-COVA rea E 1 ig ibility-A p p rova $1 . p d f \&$ s a $=$ D\&ust $=1589812822110000 \& u s g=A F Q j C N F v 3$ eoe 1 nfQKVW0rC5ktE0Tj99b9Q. Published 2020. Accessed 11 May 2020.

23. The United States Department of Agriculture. Texas area eligibility approval. March 30, 2020. https://www.google. com/url? q = ht tps : / f n s-prod.azureedge. net/sites/default/files/resource-files/TX-CN-COVAreaEligibility-A p prova $1 . p d f \& s a=$ $\mathrm{D} \& \mathrm{ust}=1589812822111000$ \& u s g = AFQjCNHaiKuwgHAKsQcdJeAkfiMvDLuZqg. Published 2020. Accessed 11 May 2020.

24. Caspi CE, Sorensen G, Subramanian SV, Kawachi I. The local food environment and diet: a systematic review. Health Place. 2012;18(5):1172-87. https://doi.org/10.1016/j. healthplace.2012.05.006.

25. Turner L, O'Reilly N, Ralston K, Guthrie JF. Identifying gaps in the food security safety net: the characteristics and availability of summer nutrition programmes in California, USA. Public Health Nutr. 2019;22(10):1824-38. https://doi. org/10.1017/S1368980018004135.

26. US Census Bureau. Top 10 largest school districts by enrollment and per pupil current spending. https://www. census.gov/library/visualizations/2019/comm/largestschool-districts.html. Accessed 1 July 2020.

27. No Kid Hungry. Summer meals. http://bestpractices. nokidhungry.org/programs/summer-meals. Accessed 5 December 2020.

28. No Kid Hungry. Emerging strategies and tactics for meal service during school closures related to the coronavirus. h t t p : / / b e s t p ractices. nokidhungry. org/sites/default/files/2020-04/StrategiesforNonCongregateMealsDuringCoronavirusClosures_4-30.pdf. Accessed 22 July 2020.

29. Cupples Cooper C. Emergency food during natural disasters. Today's Dietician Vol. 20, No. 1, P. 34. https://www. todaysdietitian.com/newarchives/0118p34.shtml. Published 2018.

30. Feeding America. How we respond to disasters.https://www.feedingamerica.org/ourwork/disaster-food-assistance. Accessed 21 July 2020.

31. Wang ML. Relevance and uses of the getting to equity in obesity prevention framework. Am J Public Health. 2019;109(10):1321-2. https://doi.org/10.2105 /AJPH.2019.305303.

32. Kumanyika SK. A framework for increasing equity impact in obesity prevention. Am J Public Health. 2019;109(10): 1350-7. https://doi.org/10.2105/AJPH.2019.305221.

33. Lackland DT, Sims-Robinson C, Jones Buie JN, Voeks JH. Impact of COVID-19 on clinical research and inclusion of diverse populations. Ethn Dis. 2020;30(3):429-32. https://doi.org/10.18865/ed.30.3.429.

34. Dunn CG, Kenney E, Fleischhacker SE, Bleich SN. Feeding low-income children during the Covid-19 pandemic. N Engl J Med. 2020;382(18):e40. https://doi.org/10.1056 /NEJMp2005638.

35. Fleischhacker S, Campbell E. Ensuring equitable access to school meals. J Acad Nutr Diet. 2020;120(5):893-7. https://doi.org/10.1016/j.jand.2020.03.006.

36. Han B, Cohen DA, Derose KP, Li J, Williamson S. Violent crime and park use in low-income urban neighborhoods. Am J Prev Med. 2018;54(3):352-8. https://doi.org/10.1016/j. amepre.2017.10.025.

37. Mui Y, Gittelsohn J, Jones-Smith JC. Longitudinal associations between change in neighborhood social disorder and change in food swamps in an urban setting. J Urban Heal. 2017;94(1):75-86. https://doi.org/10.1007/s11524-0160107-0.

38. Cullen D, Blauch A, Mirth M, Fein J. Complete eats: summer meals offered by the Emergency Department for Food Insecurity. Pediatrics. 2019;144(4):e20190201. https://doi. org/10.1542/peds.2019-0201.

39. Laurie M. tisch center for food nutrition \& and policy. serving students during the coronavirus: best practices. https://www.tc.columbia.edu/tisch/blog/news/servingstudents-during-the-coronavirus-best-practices/.Accessed 22 July 2020.

40. US Food and Drug Administration. Best practices for retail food stores, restaurants, and food pick-up/delivery services during the COVID-19 pandemic. https://www.fda. gov/food/food-safety-during-emergencies/best-practicesretail-food-stores-restaurants-and-food-pick-updeliveryservices-during-covid-19. Accessed 22 July 2020.

41. Fortson J, James-Burdumy S, Bleeker M, et al. Impact and implementation findings from an experimental evaluation of playworks: effects on school climate, academic learning, student social skills, and behavior.; 2013. http://www.rwjf. org/content/dam/farm/reports/evaluations/2013/rwjf405971.

42. Loopstra R, Tarasuk V. Severity of household food insecurity is sensitive to change in household income and employment status among low-income families. J Nutr. 
2013;143(8):1316-23. https://doi.org/10.3945 /jn.113.175414.

43. Bowen GA. Document analysis as a qualitative research method. Qual Res J. 2009;9:27-40. https://doi.org/10.3316 /QRJ0902027.

44. Fereday J, Muir-Cochrane E. Demonstrating rigor using thematic analysis: a hybrid approach of inductive and deductive coding and theme development. Int J Qual Methods. $2006 ; 5$ (1):80-92. https://doi.org/10.1177 $/ 160940690600500107$.

45. United States Department of Agriculture. United States Department of Agriculture Economic Research Service. https://www.ers.usda.gov/data-products/food-accessresearch-atlas/documentation/. Accessed 7 July 2020.

46. Chicago Public Schools. CPS stats and facts. https://cps. edu/About CPS/At-a-glance/Pages/Stats and facts.aspx. Accessed $1 \overline{7}$ June 2020.

47. Los Angeles Unified School District. Los Angeles Unified School District Facebook Page. https://www.facebook. com/LosAngelesSchools/. Accessed 13 May 2020.

48. Houston Independent School District. 2019-2020 Facts and figures. https:// w w w h o us ton is d. org/site/handlers/filedown load. ashx $?$ moduleinstanceid $=48525 \&$ dataid $=273232$ $\&$ FileName $=2019-2020$ FactsFigures.pdf. Accessed 20 May 2020.

49. Houston Independent School District. HISD to relaunch food distribution efforts on April 6 with centralized packing hub. https://blogs.houstonisd.org/news/2020/04/01/hisd-torelaunch-food-distribution-efforts-on-april-6-withcentralized-packing-hub/. Accessed 20 May 2020.

50. Chicago Public Schools. All CPS Schools to Offer Free Meals for Pick Up During Closure Beginning Tuesday, March 17. https://www.cps.edu/press-releases/all-cpsschools-to-offer-free-meals-for-pick-up-duringclosurebeginning-tuesday-march-17/. Accessed 13 May 2020.

51. Chicago Public Schools. CPS meal sites. https://cps. edu/coronavirus/Pages/mealsites.aspx. Accessed 13 May 2020.

52. Houston Independent School District. A Special Message from Interim Superintendent of Schools Grenita Lathan. https://www.houstonisd.org/site/handlers/filedownload. ash $\mathrm{x}$ ? moduleinstanceid $=294076 \&$ dataid $=273995$ $\&$ FileName $=031620$-helpinghands.pdf. Accessed 12 March 2020.

53. Community Impact Newspaper. Houston ISD abruptly halts food distribution program after suspected COVID-19 case. https://communityimpact.com/houston/heights-river-oaksmontrose/education/2020/03/25/houston-isd-abruptly-haltsfood-distribution-program/. Published March. Accessed 25 March 2020.

54. Carpenter J. Houston ISD plans to restart food distribution at five campuses next week. Houston Chronicle. https://www. houstonchronicle.com/news/education/article/HISD-planfood-distribution-schools-five-campus-15172016.php. Accessed 13 May 2020. Published April 1, 2020.

55. County of Los Angeles. COVID-19: children, families \& schools. https://covid19.lacounty.gov/covid19-2-2/childrenand-families/. Accessed 13 May 2020.
56. Los Angeles Unified School District. What to do while Los Angeles Unified schools are closed in response to the coronavirus: Grab \& Go Food Centers distribute free meals to students. https://achieve.lausd.net/resources. Accessed 13 May 2020.

57. New York City Department of Education. Regional enrichment centers. https://www.schools.nyc. gov/enrollment/enrollment-help/regional-enrichmentcenters. Accessed 13 May 2020.

58. Dedman B. DoorDash partners with Department of Education to deliver food to medically homebound students. A m N e w Y ork. h t t p s : / / w w w . a m n y. $\mathrm{com} /$ coronavirus/doordash-partners-with-department-ofeducation-to-deliver-food-to-medically-homeboundstudents/. Accessed 13 May 2020.

59. New York City Department of Education. New York City schools meal sites. https://www.schools.nyc.gov/schoollife/food/free-meals. Accessed 12 May 2020.

60. Kinsey EW, Hecht AA, Dunn CG, et al. School closures during COVID-19: opportunities for innovation in meal service. Am J Public Health.

61. Shanks CB, Harden S. A reach, effectiveness, adoption, implementation, maintenance evaluation of weekend backpack Food assistance programs. Am J Health Promot. 2016;30(7):511-20. https://doi.org/10.4278/ajhp.140116QUAL-28.

62. United States Department of Agriculture. Summer food service program FAQs. https://www.fns.usda. gov/sfsp/frequently-asked-questions. Accessed 30 July 2020.

63. Larson NI, Story MT, Nelson MC. Neighborhood environments: disparities in access to healthy foods in the U.S. Am J Prev Med. 2009;36(1):74-81.e10. https://doi.org/10.1016/j. amepre.2008.09.025.

64. Hoffman V, Srinivasan M, Levin M, Scarmo S. Operating school meal programs in rural districts: challenges and solutions.J Child Nutr Manag. 2018;42(1) https://schoolnutrition.org/uploadedFiles/5_News_and Publications/4 The Journal_of_Child_Nutrition_and Management/Spring_2018/Operating-School-Meals-inRural-Districts-Challenges-and-Solutions-Spring2018.pdf

65. EdSource. California food banks partner with schools to serve families of students. https://edsource.org/2020 /california-food-banks-partner-with-schools-to-servefamilies-of-students/627322. Published 2020. Accessed 18 May 2020.

66. CNN. Where some of the country's biggest school districts stand on reopening schools. https://www.cnn.com/2020/07 /20/us/schools-reopening-at-home-parents-choice-wellnesstrnd/index.html. Published 2020. Accessed 21 July 2020.

67. United Nations. 'Country-driven' approach needed to limit COVID-19 damage to food security. UN News. https://news.un.org/en/story/2020/07/1068361. Published 2020. Accessed 21 July 2020.

Publisher's Note Springer Nature remains neutral with regard to jurisdictional claims in published maps and institutional affiliations. 